\title{
¿ILUSORIO EN COMPARACIÓN CON QUÉ? RORTY, DAVIDSON Y LA POSIBILIDAD DE UNA INDAGACIÓN PRAGMATISTA SOBRE EL ESCEPTICISMO AL POR MAYOR
}

\section{ILLUSORY BY COMPARISON TO WHAT? RORTY, DAVIDSON AND THE POSSIBILITY OF A PRAGMATIST INQUIRY ABOUT WHOLESALE SKEPTICISM}

\author{
JosÉ MARÍA FILGUEIRAS NODAR ${ }^{*}$ \\ Universidad del Mar. Huatulco, México
}

RESUMEN: Este artículo explora las consecuencias de una conclusión que Rorty halla en la obra de Davidson (a saber, que el escepticismo generalizado carece de sentido, por necesitar siempre de un patrón de comparación -o trasfondo de creencias verdaderas), analizando tres escenarios que aparecen comúnmente en los debates sobre el escepticismo: los sueños, las alucinaciones y los cerebros en una cubeta. Tal análisis mostrará que ninguno de estos casos es capaz de iniciar una investigación susceptible de considerarse justificada por pragmatistas como Peirce o Dewey. Después de ello, el texto trata la aparente posibilidad que existe de llevar al extremo las dudas escépticas, lo cual conducirá a exponer ciertos condicionamientos históricos de la cartesiana Concepción Absoluta de la Realidad.

PALABRAS ClAVE: Rorty, Davidson, sueños, alucinaciones, cerebros en una cubeta.

ABSTRACT: This article explores the consequences of a conclusion that Rorty found in Davidson's work (namely, that generalized skepticism doesn't make sense, because it always need a pattern of comparison -or background of true beliefs), by analising three scenarios usually appeared

\footnotetext{
*E-mail: metralatam@hotmail.com
} 
in debates about skepticism: dreams, hallucinations and brains in a vat. Such analysis will show none of these three cases could be capable of starting an inquiry that pragmatists like Peirce or Dewey would consider as justified. After that, the text deals with the apparent possibility of taking skeptical doubts to the extreme, which will lead to show certain historical conditionings of Cartesian Absolute Conception of Reality.

KEYWORDS: Rorty, Davidson, dreams, hallucinations, brains in a vat.

\section{Introducción}

Especialmente desde su segunda “pleamar” (De Olaso, 1999), resultante del impacto de la filosofía de Descartes, el escepticismo ha representado una de las principales preocupaciones, si no la mayor, para la epistemología. De hecho, esta afirmación puede ubicarse en el contexto proporcionado por las afirmaciones de quienes, como Richard Rorty, piensan que la propia epistemología, tal y como se ha entendido en toda la época moderna y gran parte de la contemporánea, depende en un sentido fundamental de la aportación cartesiana $^{1}$, la cual, a su vez, podría caracterizarse simplificadamente como la búsqueda de una manera de acallar de manera definitiva al escéptico.

Una de las herramientas utilizadas en esta búsqueda han sido los denominados 'argumentos trascendentales', , que se volvieron un arma decisiva en el ambiente filosófico

\footnotetext{
${ }^{1}$ Michael Williams $(2000,191)$ denomina “Tesis de la Emergencia” a la concepción rortiana según la cual "no es que la epistemología adquiera un nuevo nivel de importancia en el período que va de Descartes a Kant, sino que es en ese período cuando la materia es inventada. Antes de Descartes [...] no existe tal materia".

${ }^{2}$ Éstos, según Charles Taylor (1979, 151), “arrancan de alguna característica de nuestra experiencia que ellos consideran como indudable [...] Entonces avanzan hasta una conclusión más fuerte, concerniente a la naturaleza del sujeto o su posición en el mundo. Este movimiento se realiza a través de un argumento regresivo, de modo que la conclusión más fuerte deba cumplirse para que sea posible el hecho indudable de la experiencia”. Taylor propone como ejemplo prototípico de esta clase de argumentaciones la Deducción Transcendental llevada a cabo por Kant en la Crítica de la razón pura. El hecho indudable del cual parte Kant es que, como explica Taylor, si no fuéramos capaces de distinguir entre la experiencia de un orden objetivo y subjetivo de las cosas, tendríamos experiencias que no serían experimentadas como experiencias de algo, de modo que serían experiencias sin objeto, lo cual es imposible. Partiendo de este hecho, que considera indudable, Kant avanza de una manera rápida hasta considerar que la experiencia de un objeto requiere de una unidad coherente de las representaciones que la conforman. Esta estrategia, que de modo ligeramente diferente vuelve a utilizar en la segunda edición de la Crítica, es considerada por Taylor $(1979,52)$ como "el primer paso de un argumento transcendental, una regresión desde una característica incuestionable de la experiencia a una tesis más fuerte como la condición de su posibilidad”. Barry Stroud (1968) completa la caracterización de Taylor, al decir que la estrategia seguida por esta clase de argumentos para hacer frente al desafío escéptico es asegurar la necesidad de ciertos conceptos, sin los cuales no podría haber pensamiento o
} 
posterior a Descartes, no sólo a causa de Kant, a quien puede considerarse con justicia el inventor de la estrategia transcendental, sino también por muchos otros que siguieron sus pasos. En ese sentido, coincido con quienes afirman que muchas de las ideas de Wittgenstein (y con él de la filosofía analítica) constituyen actualizaciones de la estrategia trascendental en el siglo $\mathrm{XX}^{3}$. Sin ánimo de menospreciar el valor de los argumentos trascendentales, así como el importante papel que han jugado en la historia del pensamiento epistemológico, creo también que éste, al centrarse en dichos argumentos, ha dejado pasar relativamente desapercibido a todo un grupo de consideraciones de carácter empírico ${ }^{4}$ que también podrían servir para acallar al escéptico. Algunos de estos argumentos, como veremos, tienen que ver con el nivel fenoménico de nuestra experiencia personal, otros se apoyarán en resultados de las ciencias, mientras que algunos más adoptarán la forma de reflexiones históricas, las cuales, al sugerir el origen de los problemas filosóficos que están en juego, podrán iluminar partes sensibles de los mismos ${ }^{5}$. A mi juicio, algunas de estas consideraciones resultan compatibles en un alto grado con la adopción de una perspectiva pragmatista en epistemología, algo que trataré de mostrar a lo largo del presente artículo, el cual arranca de una argumentación que Rorty extrae de los escritos de Davidson y trata de ubicarla ante el trasfondo de una concepción pragmatista muy conocida, como es la referente a la necesidad de justificar nuestras dudas no menos que nuestro conocimiento. Tal concepción será el principio ordenador de este texto, dedicado a explorar desde esta perspectiva tres casos muy conocidos, que suelen aparecer casi siempre en los debates sobre el escepticismo, como son la diferencia entre sueño y vigilia, entre alucinación y percepción, y el experimento mental de los “cerebros en cubetas”, ninguno de los cuales

experiencia. Semejante modus operandi, en mi opinión, da a los argumentos trascendentales una apariencia muy sólida, a la que contribuye su carácter apriorístico.

${ }^{3}$ Esta es la opinión de Taylor (véase 1979, 152) y de Rorty (véase p. ej. Autor, 2007, §2.6), entre otros.

${ }^{4}$ Desde luego, existen muchas otras maneras de abordar el escepticismo, a favor y en contra, que no son trascendentales pero tampoco se parecen a las presentadas en este texto. Stroud (1984) ofrece un panorama ya clásico de algunas de ellas.

${ }^{5}$ Como tendremos oportunidad de comprobar enseguida, tales argumentaciones pueden parecer a primera vista menos sólidas que las basadas en la estrategia trascendental, pues carecen del apriorismo y el carácter categórico de estas últimas, lo que las hace ser falibles y estar sujetas a réplicas aparentemente intuitivas, al menos si uno acepta el marco de referencia del escepticismo. De hecho, quienes aceptan tal marco de referencia probablemente consideren que esta línea de argumentación resulta ingenua. Una prueba de ello lo ofrece el tratamiento de las tesis antiescépticas de Moore efectuado por Stroud (1984, cap. 3); en este sentido, coincido con Villarmea $(1998,73)$ en que tal acusación de ingenuidad se basa en "una interpretación simplista de los escritos de Moore". No obstante, me parece que estos inconvenientes no opacan la utilidad de un tratamiento como el elegido en este artículo, afirmación que espero sea comprobada por las lectoras a lo largo del mismo. 
será susceptible de desencadenar una investigación en sentido pragmatista. El texto finalizará con algunos comentarios acerca de una réplica muy común en los debates, que los escépticos consideran erróneamente como apoyo a su enfoque, y que también estará relacionada (aunque de un modo menos directo) con el argumento que expongo a continuación.

\section{1. ¿Illusorio en comparación con qué?}

Rorty se refiere al escepticismo en diversos lugares de su obra ${ }^{6}$, varios de los cuales reflejan de un modo consciente la influencia de ciertas ideas de Davidson. Yo he decidido centrarme en un escrito dirigido al público en general, no sólo a los especialistas en filosofía, por considerar que responde a esa intención tan típicamente pragmatista de practicar la crítica cultural, introduciendo al gran público en los debates filosóficos, y también a que creo que semejante intención divulgadora hizo que Rorty tuviera que ceñirse en este texto a los aspectos más básicos del problema. Así pues, Rorty (2003) comienza su argumentación de modo que podría llegar a parecer casual, en un texto acerca de The Matrix, película que a su juicio debe gran parte de su atractivo a la influencia (“inmerecida”) que todavía sigue ejerciendo Descartes en el pensamiento contemporáneo. Esta influencia, para Rorty, se manifiesta en una serie de "quizás”7 escépticos, los cuales constituyen el principal legado cartesiano. Como es sabido, la lectura que Rorty hace de Descartes es muy negativa, y no es momento ahora de presentarla en profundidad ${ }^{8}$. A efectos de esta exposición, basta con recordar que, para Rorty, Descartes es uno de los principales autores de lo que en algunos lugares denomina la tradición platónico-kantiana, un conglomerado de esencialismo, fundacionalismo y representacionalismo (entendidos los tres términos en el particular sentido rortiano) que ha estado, de un modo u otro, ofuscando a la filosofía desde sus inicios. En mi opinión, Descartes es en este contexto el nexo entre el

\footnotetext{
${ }^{6}$ Algunos lugares de la obra de Rorty donde se pueden encontrar comentarios sobre el escepticismo o temas estrechamente relacionados son: Rorty, 1991, 29-36; 1996a,b,c; 1997, 22-25,32-33; 2000; 2001, esp. la Segunda Parte.

7 “Quizá la vida es un sueño. Quizá la realidad es completamente distinta de lo que parece ser. Quizá el lenguaje humano es inadecuado para representar esa realidad. Quizá nuestras mentes simplemente no pueden captar lo que está sucediendo. Quizá sólo somos cerebros en cubetas, alimentados por impulsos eléctricos que alteran nuestros estados cerebrales, creando así pseudo-experiencias de un mundo imaginario" (Rorty, 2003).

${ }^{8}$ Véase Autor (2007) para una exposición relativamente completa de dicha lectura y Autor (2010) para una serie de consideraciones críticas sobre la misma.
} 
fundacionalismo platónico, basado en la contemplación de las esencias, y el fundacionalismo de representaciones privilegiadas propio de la filosofía del siglo XX. La conocida imagen rortiana del Espejo de la Naturaleza expresa de manera acertada el modo en que los tres componentes de la tradición platónico-kantiana se integran de un modo coherente en el pensamiento cartesiano. Esta tradición es cuestionada por una serie de pensadores, a los que Rorty denomina de manera poco específica 'pragmatistas', incluyendo en este grupo tanto a los pragmatistas clásicos (Peirce, James y Dewey) como a otros provenientes de las tradiciones continental (Hegel, Nietzsche o Derrida) y analítica (principalmente Quine, Sellars y Davidson). Este último autor, en opinión de Rorty, es quien da el golpe definitivo a la tradición, abriéndonos a un mundo filosófico radicalmente diferente (véase Filgueiras, 2007), caracterizado básicamente por el naturalismo. En este nuevo mundo filosófico que surge de la obra de Davidson, el escepticismo es, todo lo más, un pseudoproblema.

Los artículos de Davidson que Rorty utiliza en la argumentación que hemos elegido son "Verdad y conocimiento: una teoría de la coherencia” y "Sobre la idea misma de esquema conceptual”’ Tal y como son leídos por Rorty, ambos textos apuntan a una conclusión muy clara, una argumentación bastante contundente contra cierta clase de escepticismo, expresada en el siguiente párrafo:

Lo que señala Davidson es que el escepticismo al detalle tiene sentido, mientras que el escepticismo al por mayor no lo tiene. Tenemos que conocer mucho acerca de lo que es real antes de que podamos llamar a algo una ilusión, del mismo modo que tenemos que poseer muchas creencias verdaderas antes de poder tener creencias falsas. La réplica adecuada a la sugerencia de que [algunas cosas] pueden ser ilusorias es la siguiente: ¿ilusorias en comparación con qué? (Rorty, 2003, énfasis añadido).

Creo que a nadie se le escapa la conveniencia del escepticismo que Rorty denomina ‘al detalle’, como nos muestran numerosos ejemplos de la vida cotidiana. Haciendo uso de

${ }^{9}$ Otros artículos recomendados para entender la postura de Davidson sobre el escepticismo son: Davidson 1990b, 2003a,b. 
un ejemplo ya clásico: si vamos a comprar un vehículo usado, nos conviene poner en duda algunas de las afirmaciones que probablemente haga el vendedor. El caso del escepticismo 'al por mayor', en cambio, resulta totalmente diferente. En el ejemplo que he citado, seguramente resulte útil poner en duda las afirmaciones acerca del estado general del vehículo, su kilometraje, sus prestaciones, etc. ¿Pero qué sentido podría tener el dudar de la existencia de dicho vehículo, cuando lo tenemos delante de nuestros ojos? ¿O dudar de la existencia de nuestra ciudad e incluso de nosotros mismos? Rorty parece considerar que la réplica mencionada anteriormente resulta útil para callar al escéptico, puesto que sin un patrón de comparación (en términos davidsonianos: sin un trasfondo de creencias verdaderas) no es posible especular acerca de la existencia o inexistencia de nada. Así, como veremos, en casos paradigmáticos como los sueños o las alucinaciones, el patrón de comparación vendrá dado respectivamente por la vigilia y por la percepción.

Antes de pasar al análisis de estos casos, considero que puede ser útil relacionar esta argumentación de Rorty-Davidson con una de las concepciones de base de toda la epistemología pragmatista, una idea expresada de manera seminal en Peirce (p. ej. 1988ab) y de un modo mucho más elaborado en Dewey (especialmente en la Lógica). Como es sabido, el pragmatismo entiende la investigación con base en un modelo homeostático, según el cual el organismo se encuentra ante una situación problemática y trata de buscar una solución a la misma. Desde esta perspectiva, las investigaciones se encaminan a resolver un problema concreto, restaurando así el equilibrio perdido con la aparición de dicho problema. Se trata, como puede observarse fácilmente, de un esquema muy diferente al de Descartes $(1971,118)$, quien un día, de buenas a primeras, "gozando de un seguro reposo en un apacible retiro", decide poner en duda todas sus creencias. Para los pragmatistas, esta actuación no surge de ningún problema concreto, y por ello resultaría difícil afirmar que tenga sentido. Teniendo en cuenta estas consideraciones, se entiende fácilmente que, para Peirce, la duda deba justificarse lo mismo que el conocimiento, lo cual nos conduce a considerar que habrá dudas justificadas (como las del comprador del auto usado) e injustificadas (como las del escéptico al por mayor).

Dicho esto, podríamos pensar que, tomando en cuenta este punto particular de la perspectiva pragmatista que se acaba de exponer, lo único capaz de iniciar una 
investigación acerca de la diferencia entre sueño y realidad, percepción y alucinación, etc., tal y como estos casos son utilizados por el escepticismo, sería encontrarnos con una situación en la que ambos estados sean indiscernibles. Esto quizá podría considerarse el tipo de duda concreta y justificada capaz de dar inicio a una verdadera investigación. ¿Existen semejantes situaciones? En el resto del artículo intentaré mostrar que no, al menos en lo que se refiere al ámbito de nuestra experiencia fenoménica. En mi opinión, el argumento de Rorty-Davidson que usé como punto de partida nos ha ofrecido una plataforma útil para introducirnos en el tema, pues mostrar en qué medida su conclusión se mantiene en casi todas las situaciones cotidianas nos permitirá observar de un modo relativamente sistemático que el escepticismo al por mayor no parece hallarse justificado ${ }^{10}$. Comenzaré ya con mi análisis fenoménico, en este caso de una cuestión que ha dado problemas a los teóricos del conocimiento desde la Antigua Grecia.

\section{Los sueños}

Para ubicar al sueño en relación con otros fenómenos, Niiniluoto (1992) establece una útil matriz, que tiene como ejes dos diferenciaciones, a saber, la que se da entre imaginación y percepción, por una parte, y por otra la que se da entre el estar dormidos y despiertos $^{11}$.

De acuerdo con su posición en la matriz, el sueño podría caracterizarse como un proceso imaginativo que se da mientras dormimos. Dejando a un lado tanto las resonancias aristotélicas de semejante caracterización como las numerosas objeciones y comentarios que podrían realizarse al respecto, nos preguntaremos ahora si el sueño es realmente indiscernible de la vigilia.

\footnotetext{
${ }^{10}$ Tiene la ventaja añadida de que permite relacionar la epistemología pragmatista con ciertas preocupaciones actuales de la filosofía de la percepción. Esto, a su vez, podría servir como respuesta a una posible crítica al enfoque de este artículo, en concreto a quienes afirman que a Rorty nunca le preocuparon mucho las apelaciones de corte empírico que se tratan aquí. Si bien esto parece cierto en general, también los es que tales apelaciones parecen ser coherentes con el naturalismo defendido en tantas ocasiones por Rorty.

${ }^{11}$ Debe decirse que, a pesar de que sin duda existen casos-límite que ofrecen dificultades, los criterios para establecer estas diferenciaciones son relativamente claros. La Neurofisiología, por ejemplo, nos ofrece maneras muy precisas de determinar si un sujeto está dormido o despierto. Con respecto a la segunda diferenciación, en general podemos decir que también existen criterios (como los conductuales) para conocer si el sujeto percibe o imagina: p. ej. no reaccionamos del mismo modo cuando alguien pega un grito a nuestro lado que cuando imaginamos que alguien pega un grito a nuestro lado.
} 


\begin{tabular}{|c|c|c|}
\hline & Durmiendo & En vigilia \\
\hline Imaginación & Sueño & $\begin{array}{c}\text { Fantasía } \\
\text { Ensoñación [daydream] } \\
\text { Alucinación }\end{array}$ \\
\hline Percepción & Percepción subliminal & Percepción verídica \\
& & Ilusión perceptiva \\
\hline
\end{tabular}

Matriz de Niiniluoto

Esta pregunta no surge espontáneamente, sino que depende de una serie de consideraciones filosóficas. De entrada, existe una diferenciación básica entre el sueño y la vigilia que puede ser resuelta por métodos empíricos (observando, por ejemplo, los registros de actividad cerebral, o simplemente la conducta del individuo), lo que nos llevaría a afirmar que desde una perspectiva de tercera persona existen pocos problemas para diferenciar ambos estados. Sin embargo, la filosofía se ha interesado por el sueño principalmente desde una perspectiva de primera persona. Este hecho es patente ya en el Teeteto, pero cobra una importancia fundamental con Descartes, que pone la apelación al sueño en el momento inicial de su duda metódica. Este es el sentido con que nos quedaremos en el resto de nuestro análisis, ya que con él arranca la epistemología moderna. Por ello conviene recordar el modo exacto en que Descartes realiza esta apelación:

He de considerar aquí que soy hombre y, por consiguiente, que tengo la costumbre de dormir y de representarme en sueños las mismas cosas y aun a veces cosas menos verosímiles que [los locos] cuando velan. ¡Cuántas veces me ha sucedido soñar de noche que estaba en este mismo sitio, vestido, sentado junto al fuego, estando en realidad desnudo y metido en la cama! Bien me parece ahora que, al mirar este papel, no lo hago con ojos dormidos; que esta cabeza, que muevo, no está somnolienta; que si alargo la mano y la siento, es de propósito y a sabiendas; lo que sucede en sueño no parece tan claro y tan distinto como todo esto. Pero, si pienso en ello con atención, 
me acuerdo de que, muchas veces, ilusiones semejantes me han burlado mientras dormía; y, al detenerme en este pensamiento, veo tan claramente que no hay indicios ciertos para distinguir el sueño de la vigilia, que me quedo atónito, y es tal mi extrañeza, que casi es bastante a persuadirme de que estoy durmiendo (Descartes, 1971, 119, énfasis añadido).

Regresemos ahora a nuestra pregunta: ¿realmente no hay indicios ciertos para distinguir la vigilia del sueño? ¿Realmente son indiscernibles, desde la perspectiva de primera persona, los sueños de la vigilia? No dudo que muchas personas, especialmente aquellas cuyos propios sueños sean más vívidos, tenderán a estar de acuerdo con Descartes a un nivel intuitivo. No obstante, este hecho no tiene por qué justificar las especulaciones cartesianas, en concreto su pretensión de que el verdadero conocimiento deba constituirse como tal después de superar lo que podríamos denominar prueba del sueño. Como sabemos, un pensador relativamente cercano a Descartes en el tiempo, G. W. Leibniz (1996, IV.ii.14), aunque admitía la posibilidad teórica de un sueño "tan coherente y prolongado como la vida de un hombre", también la consideraba "tan improbable como que la historia contada en un libro apareciese mezclando al azar los caracteres de la imprenta”. Por ello, proponía como criterio de realidad, al menos en lo referido a objetos sensibles, la susceptibilidad de conexión entre "lo que sucede en diferentes tiempos y lugares y en la experiencia de diferentes personas” (Leibniz, 1996, IV.ii.14). Usando este criterio, se podría diferenciar fácilmente entre el sueño y la vigilia.

Eino Kaila, por su parte, elaboró de manera sistemática alguna de las intuiciones de Leibniz. Como explica Niiniluoto (1992), Kaila establece diferentes niveles de realidad, distinguiendo, en un nivel de invarianza creciente, las experiencias y objetos perceptuales, los objetos físicos de la experiencia cotidiana y, por último, los objetos postulados por las teorías de las diversas ciencias ${ }^{12}$. Un aspecto importante que quiero destacar es que Kaila acepta la validez de lo que él denomina el 'teorema del Teeteto', es decir, el hecho de que las experiencias soñadas o imaginadas no pueden distinguirse de las reales a través de ninguna característica interna que las primeras posean y las segundas no. Pese a ello,

\footnotetext{
${ }^{12}$ Desde luego, esta categorización no tiene por qué ser compartida, y si la incluyo es únicamente porque creo que ayuda a iluminar el tema tratado.
} 
considera que este hecho no debe conducirnos al escepticismo, siempre y cuando reparemos en algo que pasó desapercibido a Descartes: la duda lógica no es igual a la incertidumbre empírica. Si bien es posible ponerlo todo en duda, generalmente no existen razones para hacerlo.

A mi juicio, esta declaración puede leerse en consonancia con la afirmación de Peirce anteriormente mencionada: la posibilidad de duda lógica no constituye una razón que justifique la duda empírica. Y es que, si nos fijamos en el nivel empírico, tendremos que reconocer que existen criterios más que suficientes para distinguir sueño y realidad. El propio Kaila nos ofrece varios candidatos capaces de lograr tal fin. Así, además de la ya citada invarianza, Kaila propone otros tres caracteres de realidad, como son la regularidad, la cuasi-legalidad y la predictibilidad, cualquiera de los cuales nos ofrecería un indicio claro para diferenciar lo que nos interesa aquí.

Regresando brevemente al argumento propuesto por Rorty, podríamos decir que el problema de Descartes tiene una doble raíz. Por un lado, aplicó lo que Kaila denomina ‘duda lógica’ cuando la incertidumbre empírica no justificaba tal aplicación. Este primer error le hizo dudar o pretender dudar de todo, pero sin tener en cuenta el trasfondo (en este caso empírico) que le permitiría hacer comparaciones adecuadas. Este trasfondo es aportado de manera fenoménica por la vigilia, pues es evidente que sólo podemos comparar los diferentes caracteres de realidad si tenemos acceso a ambos planos. Con lo expuesto hasta ahora, el caso estaría prácticamente cerrado: el sueño y la vigilia son perfectamente discernibles a nivel fenoménico. Desde una perspectiva de tercera persona, establecer tal diferenciación es una tarea extremadamente simple. Desde una perspectiva de primera persona, aunque en un momento determinado fuese difícil distinguir el sueño y la realidad, accedemos a nuestro patrón de comparación al despertarnos, y entonces ya no hay posibilidad de dudas (empíricas) al respecto. A continuación, veremos qué sucede en el caso de las alucinaciones, siguiendo a Juan C. González (2004).

\section{Las alucinaciones}

El principal mérito del análisis de este autor, a efectos de mi exposición, es el haber establecido de una manera clara el patrón de comparación entre la percepción “normal” y la 
experiencia alucinada. González parte de la idea de que gran parte de los análisis filosóficos que se han hecho sobre las experiencias alucinatorias no toman en cuenta determinados aspectos de tipo empírico y fenomenológico acerca de las mismas, y que esto ha provocado que el concepto de alucinación sea tratado de una manera sesgada. Tomar en cuenta dichos aspectos empíricos permitirá a González cuestionar la indiscernibilidad fenoménica de la experiencia alucinatoria y la experiencia perceptiva.

Para lograr esto, González presenta un catálogo de diferencias y semejanzas entre ambos tipos de experiencia. Muestra en primer lugar una serie de consideraciones acerca de la percepción, a su juicio "la función cognitiva más básica que tenemos los seres humanos, pues gracias a ella podemos establecer y mantener un contacto cognitivo con nuestro entorno -lo cual es [...] fundamental para la supervivencia” (González, 2004, 58). Posteriormente, presenta tres “rasgos funcionales básicos” (González, 2004, 58) de la percepción, que se repiten dentro de cada especie y también en diferentes especies, a pesar de todas las contingencias producto de la historia natural. Estos tres rasgos son: (1) la detección, (2) la localización y (3) el reconocimiento de objetos. González considera que la mayor sofisticación de cada rasgo con respecto al anterior es una prueba de su evolución más tardía.

En cuanto a la alucinación, luego de presentar algunas consideraciones etimológicas, González nos recuerda de dónde procede la relevancia filosófica de su estudio. Como en el caso de los sueños (y, añadiríamos, en el de los cerebros en cubetas), la tradición filosófica postcartesiana ha analizado las alucinaciones con el fin de "obtener criterios de certeza sobre la realidad bajo el argumento de que nuestro contacto sensorial con ella no basta para garantizar conocimiento” (González, 2004, 61). Es por ello que los tres casos resultan intercambiables desde esta perspectiva concreta. Aunque su análisis, que yo seguiré, está restringido a las alucinaciones, y concretamente a las de tipo visual, resultaría fácil extenderlo al estudio de otros tipos de alucinaciones, así como a otros fenómenos que están relacionados conceptualmente con éstas, como el engaño o la ilusión, a los que me referiré más adelante. Una vez expuesto esto, González $(2004,61)$ pasa a presentarnos dos ideas que apoyan la consideración tan usual de que la alucinación es una “percepción sin objeto”: la primera de ellas es que la percepción se conecta causalmente 
con el mundo, mientras que la alucinación no; la segunda, relacionada directamente con el tema de este artículo, es que la experiencia alucinatoria no se puede distinguir de forma cualitativa o fenoménica de la experiencia perceptiva o, expresado en los términos pragmatistas que hemos venido siguiendo, que sí constituye el tipo de situación susceptible de iniciar una investigación.

No trataré la crítica hecha por González al primer supuesto (que considera básicamente contradictorio), sino que me centraré en su crítica al segundo. Para mostrar que es erróneo, realiza, como ya he dicho, un comparativo entre las semejanzas y diferencias que, “en un registro empírico y fenoménico” (González, 2004, 63) se dan entre percepción y alucinación. Así, comienza destacando las siguientes características de la primera: (1) la capacidad de percibir el mundo es anterior, evolutivamente hablando, a la capacidad de experimentar el mundo; (2) la capacidad perceptiva se ha adquirido progresivamente a lo largo de la evolución; (3) la percepción es dinámica, no podremos entenderla sin tomar en cuenta su relación con la acción; (4) la percepción posee un carácter multimodal, y los perceptos son unidades; (5) la experiencia visual posee "una unidad global” (González, 2004, 64) en cuanto al campo visual: además de la unidad de los perceptos tomados uno por uno, el propio campo visual está dotado de una unidad que se puede analizar à la Husserl, de acuerdo con la relación que guardan entre sí los objetos y los eventos (existen, por ejemplo, regularidades que deben tenerse en cuenta); (6) tales relaciones y regularidades del campo visual se pueden mapear para tomar en cuenta el punto de vista del agente, de modo que el contenido de nuestra conciencia se pueda describir objetivamente, lo cual permite a su vez que las descripciones también se puedan evaluar de manera objetiva; (7) la percepción se acompaña siempre de una conducta que se corresponde con lo percibido ${ }^{13}$.

\footnotetext{
${ }^{13}$ González recalca el hecho de que, en todos los puntos citados, resulta innecesario apelar a la autoconciencia del individuo, y sólo una vez es necesario apelar a su capacidad lingüística, lo cual en mi opinión posee diversas ventajas: por un lado, como afirma el propio González, es posible extender el análisis a los animales no humanos. Por otra parte, creo que semejante ethos naturalista contribuye a alejar a alguno de los fantasmas que han estado obnubilando a la tradición filosófica desde tiempos de Descartes y también, introduciendo a botepronto una reflexión que sin duda requiere de mayor análisis, que tal vez podría mostrarnos un camino para conectar algunas intuiciones rortianas con la actual epistemología evolucionista.
} 
Por su parte, el análisis de la experiencia alucinatoria hecho por González (2004, 66) se apoya en textos de diversos autores, "individuos normales que, teniendo una buena capacidad analítica y dotes de expresión literaria, están o han estado bajo los efectos de substancias psicoactivas en situaciones más o menos controladas”. Así, manifiesta haberse fijado en los escritos de Charles Baudelaire, Aldous Huxley y otros. Uno de los primeros hallazgos de esta búsqueda, que contribuye sin duda a "disipar el aura fantástica que en el imaginario popular, y aun académico, rodea al tema” (González, 2004, 66) es que "las alucinaciones se producen normalmente con el conocimiento del individuo; esto es, el sujeto que experimenta la alucinación sabe de algún modo que está alucinando” (González 2004, 67). Esta idea, presente en la mayoría de los escritores analizados, es contrastada por González con las descripciones más o menos fantasiosas de autores como Lord Brain, quienes hablaban del tema sin un conocimiento de primera mano. González $(2004,68)$ también se hace eco de las ideas de R. K. Siegel, quien trató de analizar "los invariantes fenoménicos que son comunes a diferentes experiencias alucinógenas”, citando como ejemplo los característicos patrones simétricos del arte huichol, ligado al consumo de peyote. En las investigaciones de Siegel, nos dice González (2004:68.) “hay indicios claros de que los sujetos de su investigación mantienen de alguna forma su lucidez durante la experiencia alucinatoria”. González apoya sus afirmaciones con una referencia a la obra de Henri Michaux y también aludiendo a una intuición de Charles Duits, quien opina que la experiencia del peyote, en lugar de llamarse 'alucinógena', debería ser denominada 'lucidógena', debido a que en ella se perciben muchos más detalles que en la percepción normal. Esto desembocaría en una concepción de la alucinación como “hiper-percepción” (González, 2004, 69), muy diferente a la que aparece en el imaginario popular.

Después de su revisión de la literatura, González (2004, 70) establece las siguientes conclusiones:

1) en la experiencia alucinatoria, el mundo permanece visualmente accesible y la interacción funcional del individuo con éste se mantiene vigente, por lo que no se pierde el contacto cognitivo con la realidad; 2) las alucinaciones se distinguen de las percepciones, aunque desde el punto de vista fenoménico y espacial haya similitudes estructurales entre ellas; 3) las alucinaciones generalmente refieren a imágenes producidas espontáneamente en ausencia de estímulos externos 
[...], a ciertos patrones superpuestos en el campo visual, o a distorsiones cualitativas o espaciales de objetos y eventos que de hecho se perciben. Se debe hacer notar la importancia que cobra el pensamiento (o actividad cerebral) del individuo en la experiencia alucinatoria, así como su estado psíquico y su entorno cuando la vive, pues estos factores parecen incidir directamente en ella.

Cuando retoma la pregunta original, es decir, si la experiencia alucinatoria es fenoménicamente indistinguible de la experiencia perceptiva, la respuesta de González (2004, 70) “es claramente un ‘no’ o, por lo menos, un 'generalmente no’”. La justificación que da de esta respuesta apela a las siguientes consideraciones: (1) concebir a la alucinación como una percepción sin objeto viola un (el) aspecto funcional básico de la percepción, como es el mantenimiento del contacto cognitivo del sujeto con el mundo, una capacidad que en sus tres dimensiones ya citadas de detección, localización y reconocimiento de objetos, se ha ganado a través de la evolución; (2) a diferencia de lo que sucede en el caso de la percepción, en las alucinaciones visuales no podemos asumir distintos puntos de vista sobre el objeto, ni somos capaces de manipularlo; (3) las alucinaciones no poseen la unidad multimodal que sí está presente en la percepción; (4) la experiencia alucinatoria no posee unidad global en el campo visual: como afirma González, no otorgamos realidad a un elefante rosa por el mero hecho de estarlo alucinando; antes de ello, debemos preguntarnos cosas como si su coloración rosa es totalmente uniforme, o si oculta la parte del campo visual situada tras él, para comprobar si respeta la "sintaxis" espacial; (5) en ocasiones, la coherencia “semántica” de la alucinación no se mantiene, con lo cual "nuestro conocimiento del mundo normalmente basta para discernir entre una experiencia auténticamente perceptiva y una alucinación” (González, 2004, 71).

En mi opinión, las anteriores son razones más que suficientes para dar una respuesta negativa a la cuestión acerca de la indiscernibilidad entre la alucinación y la percepción. Esto, debemos añadir, vuelve descabelladas las dudas de estilo cartesiano. Al mismo tiempo, hace más verosímil la argumentación con que habíamos iniciado nuestro análisis: si podemos considerar ilusorias a las alucinaciones es precisamente porque la percepción normal nos ofrece un patrón con el que compararlas, algo que ha estado presente durante 
toda la exposición de González A continuación, pasaré a un tercer caso que también aparece citado a menudo en las discusiones sobre el escepticismo.

\section{Los cerebros en cubetas}

El caso de los cerebros en cubetas, que ha sido profusamente analizado, en especial desde que Putnam lo propone en Razón, verdad e historia, apenas ofrece dificultades para un análisis fenoménico como el utilizado para los sueños y las alucinaciones. Si aplicásemos semejante análisis a este caso, la respuesta a la cuestión acerca de la indiscernibilidad entre el mundo real y un mundo virtual debería ser un rotundo 'no'. La mejor tecnología de realidad virtual disponible actualmente no es capaz de ofrecernos más que una caricatura de la complejidad y riqueza de nuestro mundo. En este sentido, el análisis podría finalizar aquí, pues fenoménicamente no hay posibilidad de duda.

¿Qué pasaría si consideramos que ambas experiencias son, ex hypothesi, totalmente indiscernibles? Supongamos, pues, que una tecnología mucho más avanzada de realidad virtual fuese capaz de introducirnos en un mundo totalmente indiferenciable del nuestro, un mundo en cuyas playas por ejemplo pudiéramos sentir el mismo calor y la misma textura de la arena bajo los pies que en el nuestro, e incluso al morder una manzana virtual sintiésemos el mismo sabor que al morder una manzana real. En este caso, dado que la indiscernibilidad es precisamente la hipótesis de partida, debemos abandonar los razonamientos de corte fenoménico o empírico, y pasar a otro ámbito que ya no estará centrado en la experiencia personal, sino en la relación del escepticismo con temas como el engaño o la ilusión y en algunas consideraciones históricas, además de lo que podría denominarse un sano sentido común (similar en espíritu al de G.E. Moore o especialmente al de Thomas Reid). De cualquier forma, podremos ver que el argumento expuesto en el segundo epígrafe sigue teniendo sentido bajo estas nuevas condiciones.

Para ello, resulta útil reparar en que, pese a su aparente dificultad, este caso es relativamente fácil de adaptar al esquema explicativo que he venido utilizando. El elemento básico para lograr tal cosa es considerar la situación del cerebro en la cubeta como un caso particularmente refinado de ilusión perceptiva, la cual, aunque mucho más compleja, funciona de modo similar a una habitación de Ames o un espectáculo de magia. Cuando un 
mago presenta una ilusión, pensemos por ejemplo en una levitación, le hace creer a su público que las cosas son de una manera, aunque en realidad suceden de una forma distinta a como dicho público piensa, puesto que, en principio, éste no es capaz de distinguir si la persona está realmente levitando o no. El caso de los cerebros en cubetas, en su versión más fuerte, bien pudiera entenderse como una versión especialmente sofisticada de este tipo de ilusiones.

Creo que una posible clave para entender estos casos es que siempre debe haber alguien que sabe o puede saber lo que está sucediendo en realidad. En el caso del mago, esto es obvio; en un entorno tipo Matrix, como el utilizado por Rorty para introducir el argumento de Davidson, también debería haber, en principio, una serie de programadores que conociesen el funcionamiento del sistema. Dado que en ambos casos pueden existir sujetos que desde una perspectiva de tercera persona conozcan lo que sucede realmente, hay que admitir también que esos sujetos, cuando se enfrentan a la ilusión desde una perspectiva de primera persona (un mago que ve a otro mago hacer un truco, un programador que decide meterse a la realidad virtual que él mismo ha creado), también sabrán lo que está pasando en realidad. Puede que el reconocimiento de la ilusoriedad del entorno de los cerebros en cubetas no sea accesible a éstos, pero sí lo es, y muy fácilmente, para los creadores del entorno virtual. Alguien capaz de ver las dos perspectivas (una persona que pueda tener acceso tanto a las experiencias virtuales que son sentidas por el cerebro en la cubeta como a los códigos y mecanismos que sostienen todo el entorno) sería capaz de comprender de una manera prácticamente inmediata la diferencia entre ambas. Esta persona no tendría ninguna duda acerca de lo que sucede en los dos planos, pues conocería la lógica de los mismos; por ejemplo, un elemento del entorno podría reaccionar de manera imprevista, haciendo pensar al programador algo como “qué bien funciona ese algoritmo de conducta al azar”. En principio, tales programadores podrían proporcionar una explicación causal de cada experiencia sentida por el sujeto (sean ellos mismos u otro) que está en la cubeta, estando a su alcance el reducir estas experiencias a combinaciones de unos y ceros en el código. En mi opinión, este sencillo experimento mental aporta razones no trascendentales a favor del argumento de Rorty-Davidson, al hacernos reparar en que los programadores dispondrían de un patrón de comparación, suministrado por sus 
conocimientos de la lógica del sistema, que constituirían precisamente el trasfondo de creencias verdaderas que les permite diferenciar entre realidad e ilusión.

Desde luego, las cosas pueden complicarse más, y este hecho nos conduce a nuevos problemas. Una muestra de ello: ¿qué sucedería si se ha llegado de una manera totalmente azarosa a la situación de los cerebros en cubetas y por tanto no existe nadie que conozca el funcionamiento del sistema? Continuaré con este caso en el siguiente apartado, poniéndolo en relación con una réplica que suele aparecer con gran frecuencia en los debates sobre el escepticismo, pero debo advertir que se trata de una zona tan alejada de esa duda empírica de que habla Kaila que prácticamente imposibilita desde el mismo inicio el establecimiento de una investigación en sentido pragmatista. Sin embargo, puede ser interesante avanzar un poco más en esta dirección.

\section{Una réplica escéptica}

Como decía, después de haber mostrado en qué medida argumentos como los utilizados dejan en mal lugar la idea de que los sueños, alucinaciones e ilusiones (incluso las más sofisticadas) sean indistinguibles de sus contrapartes, debo referirme ahora a una de las réplicas más socorridas en los debates sobre el escepticismo, la cual es expresada por Stroud $(1968,242)$ con cierta ironía: "no puedes mostrarle a escéptico que no estás alucinando y por consiguiente que hay un jitomate sobre la mesa, simplemente preguntándole a tu esposa si también lo ve -alucinar las palabras de tu esposa que te aseguran que es así no resulta mejor, epistemológicamente hablando, que alucinar jitomates”. Siguiendo por este camino, deberíamos admitir que tampoco es mejor alucinar que todo mundo, o la ciencia, nos confirman la existencia de dicho jitomate. Esta característica, el hecho de que aparentemente el escéptico siempre pueda llevar la duda un paso más lejos, hasta el extremo, resulta una de las más incómodas del escepticismo. Cuando limitamos nuestro análisis a un nivel fenoménico, como he mostrado en apartados anteriores, la duda escéptica se muestra injustificada. Sin embargo, cuando se repara en esta característica, el escepticismo parece cobrar sentido de repente, hasta el punto de que parecería incluso capaz de poner en cuestión las consideraciones que he venido exponiendo en los anteriores epígrafes. 
En este punto, resulta conveniente regresar una vez más a Descartes, concretamente a un problema suscitado por lo que Bernard Williams denomina 'la Concepción Absoluta de la Realidad’. Para entender las líneas generales de esta noción de Williams (1995, 6364), supongamos dos personas A y B, cada una de ellas con su propia imagen del mundo, la cual está formada de creencias, formas de conceptualizar, experiencias, etc. Resulta claro que ambas imágenes pueden diferir con respecto a un fragmento cualquiera de conocimiento (una proposición p). Sin embargo, si ambas imágenes son conocimiento siempre existirá una manera de explicar la diferencia entre las dos, es decir, de explicar que las imágenes diferentes son imágenes de una misma realidad. Por ejemplo, si A y B observan el mismo objeto desde ángulos distintos, las imágenes que tengan del mismo pueden ser diferentes. Como es obvio, esta explicación sólo puede entenderse si disponemos de una nueva imagen del mundo, que contiene a $\mathrm{A}$ y $\mathrm{B}$, junto con sus respectivas imágenes del mundo. En esa situación, las propias A y B podrían adoptar esta meta-imagen, distanciándose de su anterior manera de concebir el mundo. Según Williams, la idea de una Concepción Absoluta de la Realidad surge al reconocer que este proceso de formación de meta-imágenes parece susceptible de prolongarse indefinidamente.

En mi opinión, es más plausible aceptar la posibilidad de una semejante Concepción Absoluta (la cual está relacionada de un modo esencial con el mecanismo de la duda metódica, como veremos) cuando se parte de unas coordenadas teológicas. Al respecto, resulta curioso que la clave de arco del pensamiento cartesiano, en lo que atañe a los temas aquí tratados, sea el viejo ‘argumento ontológico' de San Anselmo, el cual permite a Descartes demostrar la existencia de ese Dios que a su vez garantiza la correspondencia de las ideas adventicias con los objetos del mundo externo. Por supuesto, reconocer esto no es decir nada nuevo: el que Descartes necesite a Dios en su sistema es algo que fue patente ya para algunos de los comentaristas iniciales de las Meditaciones, y con el paso del tiempo se ha convertido casi en un tópico de la literatura sobre el pensamiento cartesiano. Sin embargo, creo que la reflexión sobre este punto todavía puede darnos resultados interesantes, especialmente cuando se relaciona con la perspectiva pragmatista que hemos venido considerando. 
Uno de ellos sería hacernos ver la duda metódica, desde esta perspectiva, como un mecanismo que también necesita de la idea de Dios, en el siguiente sentido: Descartes trata de regular las condiciones para que algo sea considerado conocimiento, y lo hace a través de una hiperbólica exigencia de garantías. Debido a la importancia que en su época se daba a la idea de Dios, tal vez estuviese justificado para Descartes el preguntarse por un genio o por un Dios engañador. Cualquier afirmación que resistiese esa prueba podría ser considerada conocimiento, sin que cupiera la posibilidad de albergar duda alguna. Pero, evidentemente, se trata de una justificación que depende tan sólo de contingencias históricas y biográficas, y no tiene por qué aceptarse hoy en día. En las coordenadas actuales, introducir a Dios en nuestras consideraciones epistemológicas no parece tener demasiado sentido para mucha gente. Si introducimos en nuestras consideraciones sobre el conocimiento a un genio o un Dios engañador, fácilmente podríamos pensar en hipótesis alternativas (por ejemplo, un “meta-Dios” que engañe a ese Dios, convirtiendo en realidad lo que éste considera que son nuestras alucinaciones). Y podemos hacerlo, porque en el fondo, gracias a Darwin y a otros, ya no consideramos a Dios como un actor principal en el juego epistemológico. Si Descartes no toma en cuenta esta posibilidad u otras por el estilo, ello puede deberse a que tiene en cuenta un mecanismo fundamentalmente similar a lo expresado por el argumento ontológico, que considera a Dios como el ser más grande que el cual nada puede ser pensado, de modo que acaba por representar el máximo garante tanto de la realidad como del conocimiento que podamos tener de ella. Nosotros, en otras coordenadas históricas, podemos tomar en cuenta sin asustarnos hipótesis como las mencionadas anteriormente. Tampoco nos asusta el azar, y esto nos hace regresar a la pregunta por los cerebros en cubetas, en su versión más fuerte.

Al respecto, quisiera comentar varias cosas. Decir que hemos llegado es esa situación “por azar” presupone una explicación alternativa (que podría entenderse sin forzar mucho las cosas como ‘un patrón de comparación’), en la cual se ha llegado a esa situación de una forma no azarosa, es-decir, de una manera necesaria o al menos sujeta a cierta lógica. De entrada, semejante consideración podría considerarse una mera “vacación” del lenguaje epistemológico, pidiendo explicaciones que son, en esencia, imposibles de conseguir, sobre lo que efectivamente hay en el mundo. Por otra parte, y esto se relaciona directamente con lo expuesto acerca de Descartes, esta petición de explicaciones bien 
podría considerarse una añoranza por lo que Putnam denomina el punto de vista del ojo de Dios. Entonces, en este caso el patrón de comparación al que nos hemos estado refiriendo vendría dado por dicho punto de vista, de modo que si éste no existe, o es inaccesible, no es posible lograr una comprensión efectiva de la realidad. Más aun, si aceptamos que los seres humanos y nuestro entorno somos producto de millones de años de evolución, tendremos que reconocer que, expresado un tanto crudamente, la propia realidad puede ser considerada un entorno similar al de los cerebros en cubetas, en su versión más difícil, y nadie (nadie más que los místicos) considera esto un problema especialmente preocupante. Los casos que sí nos preocupan o bien se ajustan al esquema previamente esbozado, en el cual siempre existe alguien que sabe lo que pasa, o bien son manifestaciones de nostalgia por una época en la cual se daba más importancia a la idea de Dios, y en general a los absolutos de cualquier clase.

¿Cómo se relaciona esto con el argumento de Rorty-Davidson? Dicho de manera un tanto tosca, pero coherente con el pensamiento de Rorty: cuando aceptamos el juego de lenguaje del escepticismo generalizado o al por mayor nos vemos envueltos en problemas que ya no nos corresponden históricamente. Tal vez nunca podamos satisfacer los requisitos para eliminar de un golpe la duda lógica, que parecería susceptible de llevarse al infinito, o hasta ese firme límite constituido por el Dios de San Anselmo. Pero asumir este hecho no implica que debamos aceptar el escepticismo generalizado; al contrario, podemos pensar que, en el estado actual del conocimiento, semejante duda hiperbólica no está justificada. El nivel empírico, como he tratado de mostrar, no ofrece situaciones capaces de suscitar una investigación concreta y definida, al estilo pragmatista, sobre la diferencia entre realidad e ilusión. Cuando nos enfrentamos a situaciones como las de los cerebros en cubetas, especialmente en su versión más radical, reparamos en que el único posible patrón de comparación vendría dado por el punto de vista del ojo de Dios. De este modo, o bien aceptamos que, parafraseando a Heidegger, "sólo un Dios podrá salvar a nuestro conocimiento”, o sencillamente dejamos de preocuparnos por el asunto. Probablemente Rorty, en vista de alguna de sus incendiarias declaraciones (“realistas, maduren”), optase por advertir a los escépticos al por mayor algo semejante a lo que Thomas Reid (1998) aconsejaba socarronamente a su paisano David Hume y quienes lo seguían: sus problemas 
no se resolverán con argumentos, sino con ejercicio físico, un buen reposo y una alimentación adecuada...

\section{Bibliografía}

DAVIDSON, D. (1990a), “Sobre la idea misma de esquema conceptual”, en De la verdad y de la interpretación. Fundamentales contribuciones a la filosofía del lenguaje. Barcelona, Gedisa, pp. 189-203.

— (1990b) “El método de la verdad en metafísica”, De la verdad y de la interpretación. Fundamentales contribuciones a la filosofía del lenguaje. Barcelona, Gedisa, pp. 204-218.

— (1992) "Verdad y conocimiento: una teoría de la coherencia”, Mente, mundo y acción. Claves para una interpretación, Barcelona, Paidós, pp. 73-97.

— (2003a) “Conocer nuestra propia mente”, en Subjetivo, intersubjetivo, objetivo, Madrid, Cátedra, pp. 41-71.

- (2003b) “Tres variedades de conocimiento”, en Subjetivo, intersubjetivo, objetivo, Madrid, Cátedra, pp. 280-300.

DE OlAso, E. (1999), “Certeza y Escepticismo”, en Villoro, L. (ed.), El conocimiento, Madrid, Trotta, pp. 107-133.

Descartes, R. (1971), Discurso del Método y Meditaciones Metafísicas, México, Editora Nacional.

DEWEY, J. (1981), The Later Works of John Dewey, 1925-1953, Carbondale \& Edwardsville, Southern Illinois University Press,

FAERNA, A.M. (1996), Introducción a la teoría pragmatista del conocimiento, Madrid, Siglo XXI.

FILGUEIRAS NODAR, J. M. (2007). La reconstrucción historiográfica de la epistemología en

Richard Rorty. Tesis doctoral. Cuernavaca, México: Facultad de Humanidades, Universidad Autónoma del Estado de Morelos.

— (2010). “¿El inventor de la mente? Una crítica a la lectura rortiana de Descartes”, Signos Filosóficos, XII/23, pp. 69-97.

GONZÁLEZ GONZÁLEZ, J.C. (2004), “El argumento de la alucinación revisitado”, Acta comportamentalia, 12, pp. 55-73. 
KANT, I. (2003), Crítica de la razón pura, Madrid, Alfaguara.

LeIBNIZ, G.W. (1996), New Essays on Human Understanding, Cambridge, Cambridge University Press.

MCDERMID, D. (2000), “Does Epistemology Rest on a Mistake? Understanding Rorty on Scepticism”, Crítica. Revista Hispanoamericana de Filosofía, Vol. XXXII, No. 96, pp. 3-42.

MoOre, G.E. (1993a), “A defence of common sense”, en Baldwin, Th. (ed.), Selected Writings, Londres, Routledge, pp. 106-133.

— (1993b) "Proof of an external world”, en Baldwin, Th. (ed.), Selected Writings, Londres, Routledge, pp. 147-170.

NiInILUOTO, I. (1992), “Dream and reality”, conferencia presentada en el XI Congreso Europeo sobre Investigación del Sueño, en Helsinki, el 6 de julio.

$<$ http://www.valt.helsinki.fi/kfil/matti/niiniluoto.pdf, 21.2.2010>

PEIRCE, C.S. (1988a), “Cómo esclarecer nuestras ideas”, en Vericat, J. (ed.), El hombre, un signo (El pragmatismo de Peirce), Barcelona, Crítica, pp. 200-223.

— (1988b) “La fijación de la creencia”, en Vericat, J. (ed.), El hombre, un signo (El pragmatismo de Peirce), Barcelona, Crítica, pp. 175-199.

PutnAm, H. (1988), Razón, verdad e historia, Madrid, Tecnos.

REID, T. (1998), La filosofía del sentido común. México, UAM-Azcapotzalco.

RORTY, R. (1991), Contingencia, ironía y solidaridad, Barcelona, Paidós.

— (1996a) "El mundo felizmente perdido”, en Consecuencias del pragmatismo, Madrid, Tecnos, pp. 60-78.

— (1996b) “El escepticismo en Cavell”, en Consecuencias del pragmatismo, Madrid, Tecnos, pp. 258-273.

— (1996c) “Pragmatismo, Davidson y la verdad”, en Objetividad, relativismo y verdad. Escritos filosóficos, Barcelona, Paidós, pp. 173-205.

- (1997) “La verdad sin correspondencia”, en ¿Esperanza o conocimiento? Una introducción al pragmatismo, Buenos Aires, Fondo de Cultura Económica, pp. 7-42.

— (2000) “Armas antiescépticas: Michael Williams versus Donald Davidson”, en Verdad y Progreso. Escritos filosóficos 3, Barcelona, Paidós, pp. 203-215. 
— (2001) La Filosofía y el espejo de la naturaleza, Madrid, Cátedra.

— (2003) “Out of the Matrix”, Boston Globe, 5 de octubre.

Stroud, B. (1968), “Transcendental Arguments”, The Journal of Philosophy, Vol. 65, No. 9, pp. 241-256.

— (1984) El escepticismo filosófico y su significación, México, Fondo de Cultura Económica.

TAYLOR, Ch. (1979), “The validity of transcendental arguments”, Proceedings of the Aristotelian Society, New Series, 79, pp. 151-165

VILlaRMeA REQUeJO, S. (1998), El problema del escepticismo en la epistemología analítica contemporánea, Tesis doctoral, Facultad de Filosofía, Universidad Complutense de Madrid. WILliAMS, B. (1995), Descartes: el proyecto de la Investigación Pura, México, UNAM-IIF. WiLLiAms, M. (2000), “Epistemology and the Mirror of Nature”, en Brandom, R.B. (ed.), Rorty and His Critics, Oxford, Blackwell, pp. 191-213.

Recibido: 23/04/2013

Aceptado: 24/07/2013 